The final publication is available at link.springer.com

\title{
ON THE NORMATIVITY OF INTENTIONS
}

\section{ABSTRACT}

Suppose you intend now to $\varphi$ at some future time t. However, when $t$ has come you do not $\varphi$. Something has gone wrong. This failing is not just a causal but also a normative failing. This raises the question how to characterize this normativity. I discuss three alternative views. On the first view, the fact that you do not execute your intention to $\varphi$ is blameworthy only if the balance of reasons pointed to $\varphi$-ing. The fact that you intended to $\varphi$ does not add to the reasons for $\varphi$-ing at $t$. On the second view, the fact that you do not execute your intention to $\varphi$ is blameworthy because you violate a requirement of rationality. Both these views have in common that they deny that intending to $\varphi$ at $t$ creates a reason to $\varphi$ at $t$. The third alternative, the one I defend, claims that you often create reasons to $\varphi$ by intending to $\varphi$.

\section{INTRODUCTION}

Suppose that at $\mathrm{t} 1 \mathrm{I}$ formed an intention to $\phi$ at $\mathrm{t} 2$. However, at $\mathrm{t} 2 \mathrm{I}$ don't $\phi$. For example, suppose that yesterday I decided to make a phone call to a colleague today. However, today I don't make that phone call. Something has gone wrong. There are two senses in which something can go wrong. First, there is a causal sense in which something can go wrong. That is, the result - my failure to make that phone call - is unexpected and does not follow the usual path of consequences. It is not a typical result of my earlier decision. This 'causal wrongness' is not what I want to discuss in this essay. Secondly, there is a normative sense in which my decision to make that phone call has gone wrong. It makes my failure not only unexpected but also blameworthy. Blame, here, is not necessarily moral. It can be morally speaking a good thing that my intention to perpetrate some evil was not carried out. Nevertheless, it is still the case that some normative failure has occurred in my failure to execute my intention. Blame is a complicated matter and a full discussion of its features and its relation to other concepts such as responsibility and freedom is the subject of a vast body of literature. In this essay, I will sidestep these issues. Instead, I will use the adjective 'blameworthy' as a placeholder for the view that the mistake or the failure in question is wrong in this broad and unspecified, normative sense.

A straightforward explanation of why my failure to make the phone call is blameworthy is the following. In adopting the intention to make the phone call, I gave myself a reason to make the phone call, which I subsequently ignored. Call this the naive explanation of the blameworthiness of my failure. If the naïve explanation is correct, then it must be the case that intentions give reasons. Failure to act upon these reasons explains the blameworthiness involved in not executing intentions.

Most authors, however, reject the naïve explanation. In one of his first papers on practical reasoning John Broome expresses the rejection as follows:

The view that intentions are reasons is implausible. If you have no reason to do something, it is implausible that you can give yourself a reason, just by forming the intention of doing it. How could you create a reason for yourself out of nothing? Suppose, say, that you have no 
reason either for against doing some act, and you happen to decide to do it. Now you intend to do it. So now, if intentions are reasons, you have a reason to do it. Since you have no contrary reason not to do it, the balance of reasons is in favour of your doing it. You now actually ought to do it, therefore. But this is implausible. It is implausible that just deciding to do something can make it the case that you ought to it, when previously that was not the case. $^{1}$

Broome calls it the bootstrapping objection, in honor of Michael Bratman, who raised it in his Intentions, Plans and Practical Reason. ${ }^{2}$ Broome's counter-example in the quote may not be the strongest. Most authors give the example of evil intentions to motivate the bootstrapping objection. For example, suppose I intend to avail myself of an inheritance by poisoning my rich uncle. On the naïve explanation I now have a reason to poison my rich uncle that I did not have before and this seems objectionable as there is no reason to poison my uncle. Examples like this explain why the bootstrapping objection is widely shared in the literature. ${ }^{3}$ Though this objection is prevalent, it also poses a puzzle to most theorists, for intentions matter in one's deliberation. Or more generally, the ends that the agent has adopted make a difference - a normative difference - to his practical deliberation. The problem, then, is how that could be the case if intentions are not reasons. How can the adoption of an intention make a difference in our reasons for action at the time of action if an intention is not a reason? This raises a challenge for those who reject the naïve explanation. The phenomenology suggests that intentions make a normative difference. At the same time, the bootstrapping objection suggests that intentions are not reasons. The challenge then is how to avoid this apparent dilemma

There are, roughly, two types of answers to the challenge in the literature. The first answer says that intentions are not normative at all but that they merely report the reasons for action. This explains why they seem to be normative. The second answer holds that there is more than one kind of normativity and that the normativity of intentions is different from the sort of reasons that Broome is talking about in the quote above. In this paper, I argue, first, that both answers leave something to be desired. Secondly, I argue that an elaboration of naïve explanation is plausible and that this version gives us the tools to explain the normative nature of intentions. For reasons that will become clear, I call this version the authority view. The upshot of that argument is that the bootstrapping objection is not as devastating as the literature suggests it is and that the apparent dilemma is just that: merely apparent.

In the next sections, I introduce some theoretic background to the discussion. I discuss the concept of reasons, the phenomenology of intentions, and show how intentions make a

\footnotetext{
${ }^{1}$ John Broome, "Are Intentions Reasons? And How Should We Cope with Incommensurable Values?," in Practical Rationality and Preference: Essays for David Gauthier, ed. Arthur Ripstein and Christopher Morris (Cambridge: Cambridge University Press, 2001), 98.

${ }^{2}$ Michael Bratman, Intention, Plans, and Practical Reason (Cambridge: Harvard University Press, 1987), 24-27.

${ }^{3}$ E.g., Joseph Raz, "The Myth of Instrumental Rationality," Journal of Ethics and Social Philosophy 1 , no. 1 (2005); Kieran Setiya, "Cognitivism About Instrumental Reason," Ethics 117, no. 4 (2007): 649673; John Brunero, “Are Intentions Reasons?," Pacific Philosophical Quarterly 88, no. 4 (2007): 424444.
} 
difference in practical reasoning. Next, I will discuss myth theory as formulated by Joseph Raz and others. I will argue that it fails to account for the phenomenology of intention. I then proceed to discuss two flavor theory according to which the type of reasons that are generated by intentions is very different from 'normal' reasons of action and that this explains the normative phenomenology of intentions. In the last two sections, I present the authority view and compare it with myth theory and two flavor theory.

\section{REASONS AND INTENTIONS}

The phenomenology of intentions is such that they make a normative difference in our practical deliberations, or so I claimed above. I will now proceed to make this claim plausible. The argument makes two particular assumptions, first, about what a reason is and, secondly, about the nature of intentions. This will not be a knock-down argument that would convince even the most skeptical reader, for it is always possible to reject one of these assumptions. Since the assumptions are widely shared, it gives some reasons why one could accept the normative phenomenology of intentions and their role in practical deliberation.

What is a reason to $\phi$ ? In its most general (and trivial) sense, a reason to $\phi$ is a consideration that counts in favor of $\phi$-ing. ${ }^{4}$ To $\phi$ (e.g., to act or to think) for a reason it must be the case, first, that $\phi$-ing is in accordance with a reason to $\phi$. If there is a reason to $\phi$ and yet I do not $\phi$, I go against the reason to $\phi$ ceteris paribus. ${ }^{5} \mathrm{My}$ action or inaction is a failure to respond to this reason. Secondly, reasons are considerations that are such that they can be known or believed. If I $\phi$ for a reason then if, in addition to conforming to that reason, I have the insight that there is this reason to $\phi$. Finally, acting for a reason implies that the insight that there is this reason to $\phi$ motivates the agent to $\phi$.

Let me give an example. Suppose there is a reason that my teenage son should go to bed at 9PM: tomorrow is a school day, teenagers need a lot of sleep, he will have to get up early, etc. Suppose his mother tells him to go to bed - or else - and he goes. He conforms to the reason to go to bed in time, but he does not act on that reason. He goes to bed in order to avoid the harsh words of his mother. Suppose, in addition, that my son also believes it is a good thing to go to bed in time. He is aware of all the considerations in favor of his going to bed by 9PM. Again he goes to bed at 9PM but not because he believes it to be a good idea (he does) but because his mother tells him to go - or else. If it were up to him, he would watch his favorite TV show until 10PM. Only if my son goes to bed at 9PM because he believes that these are a good reasons to go to bed at 9PM and this belief somehow motivates him, he is acting for this reason. Therefore, a reason is not just a consideration in favor of something. A reason is such that it can fulfill these additional functional roles in one's deliberation as well.

\footnotetext{
${ }^{4}$ Thomas Scanlon, What We Owe to Each Other (Belknap Press of Harvard University Press, 1998), 18.

${ }^{5}$ In include a ceteris paribus condition, because it could be the case that there are other, stronger, reasons not to $\phi$, in which case a failure to $\phi$ does not imply a failure to respond to the reason to $\phi$.
} 
On this understanding of what a reason is, intentions could be reasons. There is nothing in the nature of an intention that rules out any of these functional roles: you can act as they direct, you can be aware that you have an intention and you can be motivated by your intention.

If this is how we could think of reasons, we should now turn to the idea of an intention. Consider again my failure to execute my intention to call my colleague. There are many circumstances that could explain my failure to make that phone call. It could be, for example, that at $\mathrm{t} 2 \mathrm{I}$ was being coerced into doing something else which prevented me from making the phone call. This explains why I did not make the phone call, but it does not show that my failure is blameworthy.

There are failures that are blameworthy. First, it could be that I failed to take into account that my colleague is ill and cannot answer the phone. That is, it is impossible to execute the intention, but not because of some active intervention from outside as in the case of coercion. If I was unaware of this circumstance, I may be excused ${ }^{6}$, but if I believed he is too ill to answer the phone and yet adopted the intention to make the phone call, I am blameworthy. My decision was not consistent with what I believed to be the case.

Secondly, another reason for blame could be that, in spite of my decision to make this phone call, I never made sure that I would have the means available. For example, I did not bring my cell phone, did not make sure that the battery was sufficiently charged, or did not take care that I would be in the neighborhood of a phone. In that case, there is a good explanation as to why my decision to make a phone call was never carried out, and there is some justification for blaming me as I did not pursue the necessary means to carry out my decision.

Finally, I could simply have reconsidered my decision. I may have come to believe it is not important to make that phone call, or have found something better to do at $\mathrm{t} 2$. Such reconsideration need not be justification for blame. Perhaps it was a bad idea to make that phone call and I should never have adopted the intention in the first place. Alternatively, I may have received new information in the mean time that warrants reconsideration. Arguably, in such cases I am justified in reconsidering. However, there are also circumstances in which reconsideration is blameworthy. It could be that in rehearsing the reasons for and against making that phone call now and reconsidering - again and again - I display a kind of fickleness that is blameworthy. ${ }^{7}$

These three explanations for my failure to execute my intentions - inconsistent beliefs, means-end incoherence, and fickleness - point to the various functions that intentions play in our mental lives. ${ }^{8}$ These functions are elegantly summed up by the so-called planning

\footnotetext{
${ }^{6}$ That is, I might be off the hook for not making the phone call, however, it is an open question as to whether my unawareness is a failure.

${ }^{7}$ Richard Holton, Willing, Wanting, Waiting (Oxford [Eng.] ; New York: Clarendon Press ; Oxford University Press, 2009), 121-124.

${ }^{8}$ There are more circumstances in which a blameworthy failure of the execution of one's intention occurs. One could forget one's decision or one could be weak willed in the sense identified by Richard Holton, "Intention and Weakness of Will," The Journal of Philosophy 96, no. 5 (1999): 241-262. In all
} 
theory of intention as developed by Michael Bratman, the basic elements of which are widely accepted nowadays. ${ }^{9}$ Let me rehearse the elements of that theory here, as it will inform much of our subsequent discussion.

We are rational agents, but only up to a degree. We are constrained in all kinds of ways in the exercise of our rationality. Many of these constraints are internal. We lack the wherewithal to process all the available information correctly. We have difficulties in assessing the relevance of information. In addition, there are external constraints. Often, we have limited time and energy to make our decisions. This further compromises our rational abilities.

Given these constraints, we and other creatures like us, need to adapt our deliberation processes to deal with these constraints. The answer, or rather, our answer, is that we form future-oriented intentions, which structure our deliberation. According to Bratman intentions are special mental states that are not reducible to combinations of beliefs and desires. Rather, they function in specific ways so as to meet the challenges that the constraints put on our deliberations.

To this end, intentions have certain characteristics. First, they typically are partial. That is, we rarely adopt a completely specified intention. Instead, we unburden our deliberations by the adoption of a partial intention that then is further filled in 'as we go along'. So, for example, I first set the goal of making that phone call and only then do I start deliberating about when to call. By deciding to make that phone call, I do not leave it up to the very last minute whether or not I shall call. Secondly, because of this partiality, intentions are hierarchical. The intention to adopt certain goals embeds intentions about the means to realize those goals. Once I adopt the goal of making that phone call, I can make decisions about when and where to call. The intention when to call presupposes the 'higher' intention to make that call. These two features of partiality and hierarchy allow us to deal with the constraints on our deliberation. Complex decisions are dissolved into more manageable decision problems. Deliberation about the place and time of the important phone call is postponed until the decision as to whether to make the phone call is resolved.

These features constrain on our intentions. First, intentions need to be internally consistent. That is, they need to be compatible with all that you believe about the world and about your abilities. ${ }^{10}$ What is more, intentions need to be consistent with your other intentions. Secondly, intentions need to satisfy means-end coherence.

those cases there is a blameworthy failing that may or may not be reducible to the types of failures mentioned here.

${ }^{9}$ Bratman, Intention, Plans, and Practical Reason; Michael Bratman, Faces of Intention: Selected Essays on Intention and Agency (New York: Cambridge University Press, 1999); Michael Bratman, Structures of Agency: Essays (Oxford University Press, 2007).

${ }^{10}$ Actually, this is too quick. In deliberation we take some things as 'given'. For example, in deciding whether to bring an umbrella or take a raincoat I take it as given that it will rain - even though, I might not be sure that it actually will rain. Similarly, in deliberating whether or not to take the bicycle to work, I take it that I have the stamina and skill to ride my bicycle all the way to work - even though I may not be completely sure that I can. In both cases, then, my attitude is not belief in the sense of a 'degrees-of-confidence' attitude. Neither is it the attitude of 'full belief'. Instead these attitudes are 
Intentions structure deliberation in a number of ways. First, they create the context for further deliberation and establish standards of relevance for options considered in deliberation. Once you have adopted the intention to make the phone call, you have the problem of settling upon a time. You would not face that problem if you had not made the initial decision to make that phone call. Secondly, intentions typically constrain further deliberation by placing 'filters of admissibility', on further deliberation. My decision to call my colleague at 3 PM rules out attending a faculty meeting at the same time.

Intentions can only function in these ways if they have some inertia and resist reconsideration. It is not impossible to reconsider. However, once a decision has been made and an intention has been adopted, the focus of deliberation is on other matters and the earlier decision is taken as a given constraint on further deliberation. Intentions can only constrain further deliberation in this way if they 'stay on the scene'.

Finally, it is crucial to appreciate that on this view intentions are not just mental attitudes or states that have causal consequences 'down stream'. Rather, intentions are also normative. Their phenomenology is such that comes with various commitments about how to act and how to deliberate. This means that it is not conceptually impossible to deviate from an intention.

With this rough characterization of intentions in place, we can understand how the three normative failures I outlined above are cases where my intentions failed and why this failure is blameworthy in the broad and unspecified sense. Consider first the case where I adopted the intention to call my colleague while I knew he could not answer the phone. In that case, my intention failed to satisfy the demand of internal consistency. I settled upon a course of action that was incompatible with my beliefs about the world. In the second case, where I adopted the goal of making the phone call, but omitted to bring my cell phone, my intention was not means-end coherent. Finally, the third kind of failure, where I failed to execute my intention because of continuous reconsiderations is a case where my intention failed to have sufficient inertia.

This provides the tools to appreciate the initial plausibility of the view that intentions matter normatively. According to the planning theory once one adopts an intention one submits to constraints that shape further deliberation. These constraints are normative: they are considerations to deliberate in a certain manner (e.g., being consistent with one's beliefs), to pursue certain actions (e.g., those means that are prescribed by means-end coherence), and to consider the adoption of certain ends settled (because of inertia). Such considerations

so-called 'acceptances': one takes certain things as 'given' in the context of deliberation and decides accordingly. On the other hand, one makes decisions against a background of beliefs about the world. These beliefs are beliefs in both the degrees-of-confidence sense and the full sense; in both a dispositional and actual sense - but not the acceptance sense. For example, in deciding whether or not to make that phone call, I do believe dispositionally that the moon orbits Earth and I do actually believe that the person I try to reach works at the same university as I do. See also, Michael Bratman, "Practical Reasoning and Acceptance in a Context," Mind: A Quarterly Review of Philosophy 101, no. 401 (1992): 1-15; L. Jonathan Cohen, "Belief and Acceptance," Mind 98, no. 391 (July 1989): 367-389; L. Jonathan Cohen, An Essay on Belief and Acceptance (Oxford: Clarendon Press, 1992); Bruno Verbeek, “Feasible Intentions," Unpublished Manuscript (Leiden, November 2010). 
fulfill the functional roles that reasons play in deliberation in the broad and almost trivial way I characterized reasons at the beginning of this section.

What is more, one can appreciate why the naïve view comes naturally. If intentions are essentially normative states of mind and their normativity appears to us as reasons, the conclusion is plausible that intentions give the agent reasons. Given the normative phenomenology of intentions it seems we can bootstrap reasons into existence. For example, in forming the intention to avail myself of an inheritance by poisoning my rich uncle who has named me as sole heir to his fortunes, I am committed to see to it that this intention is consistent with what I believe to be the case and with my other intentions. In case of a conflict with other intentions, I may have to give up my intention to poison my uncle, or reconsider those other intentions. Furthermore, I have given myself a reason to acquire poison and all kinds of other relevant means to my purpose. Finally, I have reason to refrain from reconsidering my plan to poison my uncle in the absence of new information. Of course, this is questionable bootstrapping: there should be no pressure to reconsider intentions that are in conflict with this new intention; there is no reason to acquire poison in order to execute my plan, and, finally, even though there is no new information, I really ought to reconsider and repudiate my plan.

\section{MYTH THEORY}

So how are we to avoid bootstrapping, while still making room for the idea that our intentions matter normatively? In this section, I will discuss the first type of answer: myth theory. ${ }^{11}$ According to myth theory, intentions do not generate normative pressure at all. The challenge for this type of answer then is to account for the normative phenomenology of intentions. Myth theory has a radical answer. This phenomenology rests on an error; an understandable error - but an error nevertheless.

The most straightforward way in which one could argue for this is as follows. There are all kinds of reasons that favor actions. Sometimes these considerations (or combinations of such consideration) are such that not just pro tanto, but also pro toto a certain course of action for a particular agent in a particular situation is favored. ${ }^{12}$ Under such circumstances such an agent should decide to perform that particular action and pursue the relevant means. A decision that issues in the formation of an intention is the result of a piece of practical deliberation - of weighing and rehearsing the reasons for and against it. This result, the intention, cannot itself be a reason for the action since that would amount to a double counting the reasons (i.e., the reasons for the action and then the reasons as contained in

\footnotetext{
${ }^{11}$ The term 'myth theory' in this connection is due to Bratman. Michael E. Bratman, "Intention Rationality," Philosophical Explorations 12, no. 3 (2011): 227-241; Michael E. Bratman, "Intention, Practical Rationality, and Self-governance," Ethics 119, no. 3 (2009): 411-443. Defenders of myth theory are Joseph Raz and Niko Kolodny. Raz, "The Myth of Instrumental Rationality"; Niko Kolodny, “Why Be Rational?," Mind 114, no. 455 (2005): 509-563.

12 I prefer the expression 'pro toto' over 'all things considered' that is popular in the literature, because it is not the consideration of reasons that is important but rather the 'weight' of all reasons (assuming that the metaphore of 'weight' is attractive). Put differently, 'all things considered' suggests that the difference with a pro tanto reason is epistemic, whereas 'pro toto' rightly suggests that the difference is metaphysical.
} 
the intention). Therefore, the intention, the end product of deliberation, does not give a reason for that action at all. Rather, the intention rapports the reasons for and against the action.

The rapport need not be definite. It could be that new information reaches the agent in which case the intention can be revised. The rapport, therefore, is an interim rapport of the reasons for and against the action. Rapports do not create new reasons: they just sum up the reasons. The error of thinking that an intention creates reasons is the error of regarding the summing up of reasons as a reason itself.

This clearly avoids bootstrapping, but is the myth view correct and does it do justice to the normative phenomenology of intentions? First we need to refine the interim report view that underlies myth theory so as to render it more plausible.

Consider the question what to do with my life. There are lots of projects that are worthy to pursue. Consequently, there are lots of reasons for all kinds of actions. There is a reason to learn to play piano; there is a good reason to study the collected works of David Hume, etc., etc. It is impossible to live up to all these reasons in the course of one lifetime. So one has to choose and opt for the best of all these projects, i.e., adopt those reasons in one's intentions that are the strongest. This presupposes that these reasons are comparable, but often they are not. It is indeterminate whether studying the piano is more important and more valuable (and hence a stronger reason) than dedicating one's life to philosophy. There is not a pro toto reason. Both are worthy causes but they are incomparable in value and, therefore, the reasons to pursue the one or the other are incomparable too. The agent, then, will have to 'pick' one or the other. ${ }^{13}$ Here reason cannot guide you other than telling you to pursue one of these projects as opposed to not pursuing valuable projects at all. Suppose you act on this reason and pick the project of studying the piano. This picking is the result of an intention, so if the interim report theory is correct, it must be the case that studying the piano is supported by reasons pro toto. But it is not: picking a worthy project to pursue is supported by reasons, but that does not mean that actually studying the piano is equally supported.

This objection shows that there are two ways of interpreting the interim report view. On the strong interpretation, the intention reports all the reasons there are. Clearly, this strong interpretation is false if there are incompatible reasons: the intention to study the piano does not reflect the reasons for dedicating one's life to helping AIDS victims. On the weak interpretation, the intention only reports one or more pro toto reasons for the action. It need not be the report of all the reasons. The intention to study the piano, even if its adoption is due to 'picking' rather than choice, does display the pro toto reason for studying the piano - but not the reasons for studying philosophy. It follows that on the weak interpretation, the intention need not be a complete report of the reasons for the action.

Long-term projects typically involve lots of smaller steps. If I adopt the project of learning to play the piano, I have to study every day. Studying every day in the absence of the overall project of learning to play the piano does not make any sense. In other words, when you

\footnotetext{
${ }^{13}$ 'Picking' as opposed to 'choosing' in the way characterized by Edna Ullmann-Margalit and Sidney Morgenbesser, "Picking and Choosing," Social Research 44 (1977): 757-785.
} 
adopt an end, you have an instrumental reason to pursue the means to that end. This reason does not exist in the absence of the intention. The question for the myth theorists then is how to think of such instrumental reasons. How can the mere fact that you picked one project give you a reason that you did not have before? The most straightforward suggestion is again that the intention gives you such instrumental reasons, but this is not open to myth theorists, as it would open the door for questionable bootstrapping.

However, myth theorists have an alternative answer. Joseph Raz has argued that the reasons to pursue the relevant means to an adopted end hold independently of the agent's intention. ${ }^{14}$ The idea is that just as there is a reason to learn to play the piano, there is a conditional reason of the form 'if you have adopted the project of learning to play the piano, you should study the piano everyday'. However, there is no general reason to pursue the means relevant to your ends. While there are reasons to learn to play the piano and conditional reasons to study everyday if you have formed the intention, there is no reason to kill one's rich uncle and no conditional reason to acquire poison if one has adopted such an intention. In this way, myth theory can explain on the one hand that intentions do not themselves give reasons, but explain why intentions matter when settling on the means to execute one's intentions without any bootstrapping either of reasons for the ends or the means for those ends.

The real problem for the interim report theory that underlies this version of the interim report view is the following. Intending to $\phi$ implies inter alia that one is settled: $\phi$-ing is the thing to do. The formation of an intention ends deliberation (at least, for the time). As we have seen in the previous section, an intention, in order to play its characteristic role in the mental life of the agent, 'stays on the scene'. In other words, intentions have inertia. Interim reports do not. They are always provisional, ready to change. Hence, intentions cannot be interim reports.

Myth theorists have an answer to this objection. In deliberating one spends precious resources (attention, time, etc.). Spending such resources on a decision raises the opportunity costs of reconsidering one's decision, since spending resources on further deliberation is reasonable only if the expected marginal value of the reconsidered intention is such that it outweighs the costs of these resources. However, the expected marginal value of continuing deliberation typically declines (assuming there is no new information, as I am assuming here throughout). Therefore, at some point, there is no reason to continue deliberating and one should settle on one's intentions.

However, this also means that one has abandoned the interim report view and with it a crucial building block of myth theory. For now it appears that intentions, or rather, the whole of the deliberations leading up to the adoption of the intentions, provide reasons against reconsidering. So this is not a suggestion that will help the myth theorist in a way that avoids bootstrapping.

Alternatively, one could argue that an intention to $\phi$ only has the causal effect of terminating deliberation (at least for now) about $\phi$-ing and that the inertia of intentions is

\footnotetext{
${ }^{14}$ Raz, "The Myth of Instrumental Rationality."
} 
not normative. Of course, this means rejecting part of the normative phenomenology of intentions as discussed above. So the normative inertia of intentions spells trouble for the way myth theory seeks to answer the challenge of avoiding bootstrapping and its explanation of the normative phenomenology of intentions.

\section{TWO-FLAVOR THEORY}

Denying that intentions are normative is not the only way to meet the challenge of avoiding the bootstrapping while accounting for the normative phenomenology of intentions. The other way is to point out that the characterization of reasons I proposed above is too broad. A more refined distinction within the category of reasons can help to come to grips with the normative phenomenology of intentions without any questionable bootstrapping.

One such a distinction is the well-known distinction between external and internal reasons. ${ }^{15}$ Roughly, external reasons reside in mind-independent facts whereas internal reasons are mind-dependent. These reasons operate independently of one another. If I am thirsty and there is a glass in front of me with a clear fluid, which I believe to be water, I have a reason an internal reason - to drink its contents. If in reality I am mistaken and the fluid is actually boric acid, I have have a reason - an external reason - not to drink its contents. There is not contradiction here as internal and external reasons can exist independent of each other. We can apply this distinction to the normativity of intentions and argue that intentions give internal reasons to the agent, but not external reasons. Then by adopting an intention I do not bootstrap new external reasons into existence, but I have brought a new internal reason into the world.

This proposal will not work, first, because defined like this, it seems that all considerations that are relevant to the agent when deliberating are internal in this sense as one of the key characteristics of reasons is that one can act upon them. Secondly, there may still be questioning bootstrapping. For example, if I formed the intention to kill my rich uncle, on this proposal, I would have bootstrapped an internal reason to kill my uncle into existence. In short, this way of carving up the category of the normative does not really help.

However, it suggests how one could hang on to the idea that intentions have normative pressure, while avoiding bootstrapping altogether. The idea is that by making a distinction between two kinds of normativity that function differently, you can avoid questionable bootstrapping. This is the central insight of John Broome's work on the requirements of rationality. ${ }^{16}$ For Broome, the central category is that of 'ought'. Within this category,

\footnotetext{
${ }^{15}$ Bernard Williams, "Internal and External Reasons," in Moral Luck, ed. Bernard Williams (Cambridge: Cambridge University Press, 1981), 101-113.

${ }^{16}$ John Broome, "Normative Requirements," Ratio: An International Journal of Analytic Philosophy 12, no. 4 (1999): 398-419; Broome, "Are Intentions Reasons? And How Should We Cope with Incommensurable Values?"; John Broome, "Practical Reasoning," in Reason and Nature: Essays in the Theory of Rationality (Oxford: Oxford University Press, 2002), 85-111; John Broome, "Reasons," in Reason and Value: Essays on the Moral Philosophy of Joseph Raz (Oxford: Oxford University Press, 2004); John Broome, “Does Rationality Give Us Reasons?," Philosophical Issues 15, no. 1 (2005): 321337; John Broome, "Wide or Narrow Scope," Mind 116, no. 462 (April 2007): 359-370; John Broome, "Reply to Southwood, Kearns and Star, and Cullity," Ethics 119, no. 1 (2008): 96-108; John Broome,
} 
Broome distinguishes reasons from requirements. Reasons are those oughts that have 'weight' and that are 'slack'. This means that they can be overruled by other 'stronger' or 'weightier' reasons but that they stay on the scene. An example could be that you ought to be kind to small children. Sometimes this is overruled by other reasons, but it does not cease to be the case that you ought to be kind to small children, for even if you have to be unkind, you should minimize your unkindness. Requirements, on the other hand, have no 'weight' and they are 'strict'. You either satisfy them or you do not. Other requirements or reasons do not outweigh them. They either apply or they don't. An example could be the requirement not to have inconsistent beliefs. ${ }^{17}$

This points to another distinctive feature of requirements. Requirements presuppose standards. For example, the standards of classical logic require you not to believe both $p$ and not-p. The standards of fencing require you to greet the opponent before the bout. Rationality is such a standard as well. Reasons on the other hand have their 'force' more or less independent from standards. There is a reason to be kind to small children, but this reason does not presuppose the existence of standards for child rearing. As we shall see, another way of making this point is to argue that requirements do not necessarily have authority.

Broome's suggestion is that the normative pressures that come with the adoption of intentions (internal consistency, means-end coherence, and inertia) are not reasons in his sense, but requirements of rationality. Intentions do not create new reasons, but they do put the agent under a requirement. This is not enough to completely rule out questionable bootstrapping as it could still be the case that by forming an intention you are now under a requirement of rationality to pursue the means, even if the intention or the necessary means are evil.

Broome, in response, makes an additional distinction in scope: both reasons and requirements can be wide-scoped or narrow-scoped. There is no Standard English to express this distinction, so I will revert to a more formal notation. Take the requirement that you ought to pursue the necessary means to your adopted ends. Let R stand for 'rationally required' then:

Wide-scope: $\mathrm{R}$ (If you adopt the end, you pursue the necessary means) Narrow-scope: If you adopt the end, R(you pursue the necessary means).

The difference between those interpretations is that the wide-scoped one does not allow for detachment whereas the narrow-scoped one does. That is, suppose you adopt an end, then, under the wide-scope interpretation, you are not allowed to infer that you are required to

"The Unity of Reasoning?," in Spheres of Reason: New Essays in the Philosophy of Normativity, ed. Simon Robertson (Oxford: Oxford University Press, 2009), 62-92.

${ }^{17}$ This points to another distinctive feature of requirements. Requirements come from standards. For example, the standards of classical logic require you not to believe both $p$ and not-p. The standards of fencing require you to greet the opponent before the bout. Rationality is such a standard as well. Reasons on the other hand have their 'force' more or less independent from standards. There is a reason to be kind to small children, but this reason does not presuppose the existence of standards for child rearing. Another way of making this point is to argue that requirements do not necessarily have authority. 
pursue the necessary means. All you can infer is that you either ought to pursue the means or give up the end. The narrow-scoped interpretation of this requirement does allow for detachment. Then, if you adopt the end, you should conclude that you ought to pursue the necessary means. ${ }^{18}$ Broome argues that the wide-scope reading of the requirements of rationality that comes with intentions is the correct one. When forming an intention you are under a wide-scope requirement of internal consistency and means-end coherence. This prevents all forms of bootstrapping by intentions for this means that there is no requirement to choose the necessary means of one's end. Rather, one is required either to choose the necessary means or give up the end and repudiate one's intention. No bootstrapping of any sort, therefore, needs to occur when forming an intention.

The distinction between reasons and requirements of rationality is widely accepted in the current literature. ${ }^{19}$ There is considerable debate about the scope of the various requirements, but that such distinction can be made is widely accepted. Similarly, there is fierce debate about the status of the requirements of rationality. Some authors argue that internal consistency and means-end coherence can be derived from standards of theoretical rationality (i.e., the standards that guide proper reasoning about beliefs), whereas others deny that this is the case. ${ }^{20}$ Regardless of those points of disagreement, it is generally agreed that one can avoid bootstrapping in the way two flavor theory suggests.

\section{PROBLEMS FOR TWO FLAVOR THEORY}

Nevertheless, there are still problems with this view. First, accepting the wide scope of rationality requirements may still lead to questionable conclusions about the rational admissibility of actions. If I intend to avail myself of an inheritance by poisoning my rich uncle, on this proposal I am required either to give up this end or purchase some poison and spike my uncle's drink. So I am still allowed to poison my rich uncle: it is one of the admissible ways of satisfying the requirement of means-end coherence. Suppose, furthermore, that I am unable to revise my intention to come into the possession of my

\footnotetext{
${ }^{18}$ Broome, "Normative Requirements," 403.

${ }^{19}$ For example, Mark Schroeder, "The Scope of Instrumental Reason," Philosophical Perspectives 18, no. 1 (2004): 337-364; Niko Kolodny, "State or Process Requirements?," Mind 116, no. 462 (2007): 371-385; Andrew Reisner, "Unifying the Requirements of Rationality," Philosophical Explorations: An International Journal for the Philosophy of Mind and Action 12, no. 3 (November 5, 2009): 243 - 260; Errol Lord, "Having Reasons and the Factoring Account," Philosophical Studies 149, no. 3 (2010); John Brunero, "Instrumental Rationality, Symmetry and Scope," Philosophical Studies 157, no. 1 (2012): 125-140.

${ }^{20}$ Gilbert Harman, David Velleman, and Kieran Setiya defend the view that these requirements are requirements of theoretical reason or 'cognitivism'; Bratman and Brunero defend 'noncognitivism'; John Broome, finally, argues that neither of these extremes is plausible. Gilbert Harman, Change in View: Principles of Reasoning (Cambridge: MIT Press, 1986); J. David Velleman, "What Happens When Someone Acts," Mind 101, no. 403 (1992): 461-481; J. David Velleman, "Epistemic Freedom," Pacific Philosophical Quarterly 70, no. March (1989): 73-97; J. David Velleman, The Possibility of Practical Reason (Oxford: Oxford University Press, 2000) Introduction; Setiya, "Cognitivism About Instrumental Reason"; Michael E. Bratman, "Cognitivism About Practical Reason (Review of Practical Reflection, by J. David Velleman)," Ethics 102, no. 1 (1991): 117-; Bratman, "Intention Rationality"; Bratman, "Intention, Practical Rationality, and Self-governance"; John Brunero, "Against Cognitivism About Practical Rationality," Philosophical Studies 146, no. 3 (2009); Broome, "The Unity of Reasoning?".
} 
inheritance through murdering the rich uncle, then it looks like it is not only admissible, but also required. ${ }^{21}$ Again, the specter of bootstrapping emerges.

There is a fair bit of discussion about what this objection actually shows about the claim that the normative pressure that an intention puts on the agent is that of wide-scoped requirements. One way of addressing this objection is the route taken by David Velleman and others, who argue that the requirements of intentions are requirements of rationality not morality or even prudence. Action need not be good or reasonable in order to be action. Since action presupposes an intention, the general permissibility of satisfying the requirement of means-end coherence by pursuing the necessary means shows that when one forms an intention, one need not form these under the guise of the good. ${ }^{22}$ However, if that is a plausible response, one starts to wonder what the problem with bootstrapping was in the first place. If it is not a problem that requirements are sometimes can be bootstrapped into existence, why argue that these requirements are wide-scoped rather than narrow-scoped? ${ }^{23}$

A second problem for the two-flavor theory more or less follows from this way out. If requirements are to be distinguished from reasons as strictly as two-flavor theory demands, and if the requirements of rationality accompany intentions, then the question readily emerges 'why be rational?' Why satisfy these requirements? Indeed, why think rationality is normative at all? It is one thing that rationality requires to be consistent in one's attitudes, but why should one treat these requirements any different than, say, the requirements of fencing or etiquette?

Two distinctions that are made by Richard Joyce, following Foot, are useful here. ${ }^{24} \mathrm{~A}$ demand can be categorical or hypothetical. A demand is categorical if its applicability does not depend on the ends of the agent who is addressed. A demand is hypothetical if its applicability depends on the ends of the agent. Similarly, a demand can be authoritative or lack authority. A demand is authoritative if the demand itself is a reason for doing as demanded. Finally, a demand lacks authority if it does not give a reason. This two-fold distinction allows us to make precise the worry that wide-scoped rationality requirements are not normative.

All requirements are categorical demands: the requirements of etiquette demand that one holds a knife in one's right hand at dinner, regardless of whether one wants to or not - the demand is still in place. However, the requirements of etiquette lack authority. There is no particular reason to hold your knife in your right hand at dinner, even though etiquette demands this categorically. Of course, there can be reasons to follow etiquette, but in the case of etiquette the reason for doing so is not that it is demanded, but for some other

\footnotetext{
${ }^{21}$ For a version of this objection, see Setiya, "Cognitivism About Instrumental Reason." A reply to this objection is in Bratman, "Intention, Practical Rationality, and Self-governance."

22 J. David Velleman, "The Guise of the Good," Nous 26, no. 1 (1992): 3-26; Bratman, "Intention Rationality." For an opposing view, see Sergio Tenenbaum, Appearances of the Good: An Essay on the Nature of Practical Reason (Cambridge University Press, 2007).

${ }^{23}$ See also Reisner, "Unifying the Requirements of Rationality."

${ }^{24}$ Philippa Foot, "Morality as a System of Hypothetical Imperatives," Philosophical Review 81, no. 3 (1972): 305-316; Richard Joyce, The Evolution of Morality (MIT Press, 2006).
} 
reason. For example, your reason can be that you want to impress your host. However, there is no reason to hold your knife in your right hand at dinner parties at each occasion regardless of such further considerations. Questions about the normativity of etiquette then are questions about its authority.

What about the requirements of rationality? Are they normative? Requirements of rationality are strict and demand consistency between intentions and one's beliefs and other intentions. And this demand is independent of the specific interests or goals of the agent. Clearly the requirements of rationality - just like those of etiquette - are categorical. However, there is a question of their authority. Is there are reason to observe these requirements in each and every occasion? Two-flavor theorists respond differently to this question about the normative authority of the requirements of rationality. Some are skeptical and claim there is no reason to be rational categorically. ${ }^{25}$ Others are officially agnostic and are open to the suggestion there is such a reason but are not convinced there is. ${ }^{26}$ Yet others claim to have found such reasons. ${ }^{27}$ It goes too far to examine the various proposals here, but one remark needs to be made. The candidate answers to this question are of two types. First, there is the view that there is a reason in general to observe the requirements that rationality demands of one's intentions, because this has better results as a policy than its counterpart. The problem with this proposal is that it amounts to a kind of rule-worship: while the policy may lead to desirable results does not imply that each and every instant where the policy is applies leads to desirable results. ${ }^{28}$ Secondly, there is the view that these particular requirements of intention rationality are tied up to being an agent and that there is a kind of inevitability about being an agent. ${ }^{29}$ The problem with this view is that it is possible to imagine an agent who does not care about being an agent, in which case the reason to be rational is not one that shows that necessarily in all cases rationality is normative. That means that two-flavor theory seems to fail in achieving its own goal of establishing that intentions necessarily come with normative pressure. ${ }^{30}$ Obviously, this is not enough to dismiss two-flavor theory. All I meant to do here is to flag some concerns that will bother any attempt of accounting for the normativity of intentions by distinguishing flavors of normativity.

\footnotetext{
${ }^{25}$ E.g., Kolodny, "Why Be Rational?".

${ }^{26}$ E.g., Broome, "Does Rationality Give Us Reasons?".

${ }^{27}$ E.g., Bratman, "Intention, Practical Rationality, and Self-governance"; Holton, Willing, Wanting, Waiting.

${ }^{28}$ Broome, "Does Rationality Give Us Reasons?"; Bratman, "Intention Rationality." For a defense see Holton, Willing, Wanting, Waiting.

${ }^{29}$ E.g., Velleman, "What Happens When Someone Acts"; Bratman, "Intention, Practical Rationality, and Self-governance." But see David Enoch, "Agency, Shmagency: Why Normativity Won't Come from What Is Constitutive of Action," Philosophical Review 115, no. 2 (2006): 169-198.

${ }^{30}$ Regardless which of these two views one accepts and regardless of how one answers these particular objections, there is the further problem that these reasons are not the sort of reasons you would expect if you take the distinctions between reasons and requirements on the one hand and narrow-and wide scope on the other seriously. If you insist that the normative pressure of intentions is really normative and at the same time avail yourself of the fact that wide-scoped demands cannot be detached, you would expect that a two-flavor theory would look, not for a requirement but for a wide-scoped reason of the form that there is a reason to see to it that if you intend the end, you pursue the necessary means.
} 
Perhaps both these problems - the problem of the admissible or even required execution of evil intentions and the problem of the normativity of intention rationality requirements can be solved. There is a more serious flaw in the dominant version of two-flavor theory: what about the normative demand for inertia on this proposal? Above, I identified three ways in which an intention can fail in a blameworthy manner. Intentions can fail to be internally consistent; can fail to display means-end coherence; or can fail due to fickleness. The answer of the two-flavor theory is to argue that intentions come with wide-scoped rationality requirements. Internal consistency and means-end coherence can be casted as wide-scoped requirements. Both demand consistency between certain attitudes: between beliefs and intentions and between goals and execution intentions respectively.

Inertia, however, is not a non-detachable wide-scoped requirement. It is simply a demand that one be settled in one's intention. It does not ask for coherence between attitudes, rather, it demands something of individual attitudes. Furthermore, it is a demand that does not fit the category of requirements in the first place. The demand for inertia is not strict: an intention can satisfy inertia even though it is repudiated. Inertia clearly belongs in the category of reasons: it has 'weight' because it can be outweighed by other considerations and it is 'slack'. To see this last point, imagine that I am faced with two mutually exclusive options $A$ and $B$, which I judge to be equally good. There is some time pressure so I do have to make a choice at $\mathrm{t} 1$ between these options. I then decide to go for $A$ and consequently adopt the intention to go for $A$ at $\mathrm{t} 3$. Suppose that at $\mathrm{t} 2$ (right after $\mathrm{t} 1$ but before $\mathrm{t} 3$ ) I receive some new information that makes me doubt my initial judgment about the value of $A$ and $B$. I then reconsider and come to the conclusion that $A$ and $B$ are indeed equally good, so I continue with my pursuit of $A$. I do not have to make a new decision. Rather, after a quick check as to whether some key beliefs and judgments relevant to the pursuit of $A$ are justifiable to me, I proceed with the original intention. It stays on the scene in other words. I would display blameworthy fickleness if I did not. This means that the reason to remain settled in my intention is slack. Of course, this reason need not be very strong, but it is there. Often the relative weakness of reasons makes us disregard these in our practical deliberations as a pragmatic measure to deal with the abundance of reason considerations only to re-emerge when stronger reasons are absent. ${ }^{31}$ I conclude that two-flavor theory cannot completely account for the normative phenomenology of intentions.

\section{THE AUTHORITY OF INTENTION}

So let us take stock of what has been accomplished so far. First, we discussed the naïve view and found it allows for questionable bootstrapping. Next, we saw that both myth theory and two-flavor theory avoid bootstrapping, at least in their more sophisticated forms. Secondly, both theories have difficulty accounting for the inertia of intentions. Myth theorists have this difficulty because they either have to deny that this inertia is normative or they have to accept that intentions do give reasons for inertia. Two-flavor theorists have difficulty with inertia because the logic of their theory requires that it be cast as a wide-scoped rational

\footnotetext{
${ }^{31}$ See also Mark Schroeder, Slaves of the Passions (Oxford University Press, 2007).
} 
requirement. However, the pressure to inertia is neither wide-scoped nor that of a requirement. This brings us to my preferred view, the authority view.

According to the authority view, the key to these problems is the exaggerated fear of bootstrapping. In what follows, I will propose a theory that, like the naive explanation, does imply that intentions sometimes bootstrap reasons into existence but that this is not problematic in those instances. It shares with myth theory the view that there is not a necessary and general pressure toward means-end coherence. It shares with two-flavor theory the rejection of the interim report theory and the endorsement of the normative nature of intentions. It differs from two-flavor theory in that the normativity of intentions is authoritative rather than categorical and that it can account for true normative inertia.

The core idea of the authority view is to take seriously the analogy between intentions and authoritative commands. ${ }^{32}$ What is the kind of authority involved here? First take the idea of political authority. ${ }^{33}$ If such an authority issues an order, you have a reason to do as you are told. People follow orders for all kinds of reasons. For example, you could do as you are told because you mom raised you that way, or you could do it out of respect for certain traditions, or, indeed, you could do as you are told for fear of the sanctions that might follow if you do not obey. In all those cases, your reason for doing as you are told is not that the political authority commanded this, but some other, independent reason. Rather than obeying the authority, you are doing what you learned as a child, are following tradition, or are avoiding sanctions. In those cases, I will say, you conform to the commands of the authority, but you do not obey them. ${ }^{34}$ Only if the very fact that the authority commanded you to $\phi$ is your reason for $\phi$-ing you obey. Genuine authority - rather than merely claimed or purported authority - then is the ability to give reasons to obey.

The decision of a genuine authority, then, is a reason to obey it. It is the decision - not the content of that decision - that is your reason if you obey. Authorities, genuine authorities, give, as Raz puts it, content-independent reasons. ${ }^{35}$ How could this be? How could the decisions of an authority make such a difference? Think of a democratically elected legislative body like a parliament. The acts of such a body are needed to make law. There

\footnotetext{
${ }^{32}$ In what follows, I rely on Bruno Verbeek, "The Authority of Norms," American Philosophical Quarterly 44, no. 3 (2007): 245-258; Bruno Verbeek, "A Limited Defense of Voluntarism in Practical Reason," Unpublished Manuscript (Leiden, February 12, 2012). A similar, but not identical, view has been developed by Govert den Hartogh, "The Authority of Intention," Ethics 115, no. 1 (2004): 6-34. Another version of this idea of authority exercised over oneself is in recent work by Ruth Chang. Ruth Chang, "Voluntarist Reasons and the Sources of Normativity," in Reasons for Action, ed. David Sobel and Steven Wall (Cambridge University Press, 2009); Ruth Chang, "Do We Have Normative Powers?" (presented at the SLACCR, St. Louis, 2010).

${ }^{33}$ The notion of authority that follows is roughly that of Joseph Raz' 'service conception of authority'. Joseph Raz, "Authority, Law and Morality," Monist: An International Quarterly Journal of General Philosophical Inquiry 68, no. 3 (1985): 295-324; Joseph Raz, The Morality of Freedom (Oxford: Oxford University Press, 1986); Joseph Raz, "The Problem of Authority: Revisiting the Service Conception," Minnesota Law Review 90, no. 4 (2006): 1003-1044.

${ }^{34}$ Note that I am using these terms in a technical meaning. The distinction is of course well known from Kant's distinction between 'acting in conformity with duty' and 'acting out of duty'. Immanuel Kant, Groundwork for the Metaphysics of Morals, ed. Lara Denis, trans. Thomas K. Abbott (Oxford University Press, 2002/1785).

${ }^{35}$ Raz, The Morality of Freedom, 35-37.
} 
may be all kinds of reasons pertaining as to which laws this body should pass, reasons having to do with justice, efficiency, etc. In addition, there are procedural rules such that when a parliament acts on these reasons and follows these procedures, there is law. The decision of the parliament is crucial for making law. Without that decision there is no law. Once the law is there, some citizens will conform to the law, out of fear for sanctions or because they think the law just and good. Laws, just like other authoritative commands and decisions, give content-independent reasons to those subjected to it. ${ }^{36}$ Law, then, makes a practical difference to those subjected to it. The passing of a law by a legislative authority bootstraps a reason - a reason to obey - into existence. That reasons is a content-independent reason: it is not the content of the law that has the legal authority, but the fact that it is the law is the reason to obey.

Political and legislative authorities are not unlimited. A parliament, for example, cannot exercise authority over areas that not within its constitutional powers. In addition to such constitutional limitations, there are considerations of justice, morality and efficiency that limit the amount and the scope of authority. However, in those areas that fall within its authority parliament has a certain amount of discretion. If setting the level of VAT is within the scope of the authority of a parliament, it has discretion as to how high that level should be. Therefore, though genuine authority is limited it also has discretion: there is a range of options, which, if commanded, give those subject to it a reason to obey.

The claim of the authority view of the normativity of intentions is that intentions have authority in exactly this sense. If I intend at $\mathrm{t} 1$ to $\phi$ at $\mathrm{t} 2$, this intention gives me a reason to $\phi$ at $\mathrm{t} 2$. This reason is content-independent. It independent of the intrinsic features of $\phi$-ing at $\mathrm{t} 2$, but it does make a difference. As a result, intentions do not merely transfer or report the reasons for $\phi$-ing, they bootstrap a content-independent reason into existence. One of the reasons that justify $\phi$-ing at $\mathrm{t} 2$ is that it is the agent's unrepudiated intention. However, just like political and legal authority the authority of intentions is limited. There are all kinds of background considerations that limit, normatively speaking, the sorts of things one can intend.

\section{THE EPISTEMIC AUTHORITY OF INTENTIONS}

Having staked the claim, we can now proceed to see if it is plausible. What we need is some explanation of how intentions can come to have such authority. To see how, we, again, turn to the inter-individual case and investigate how agents can come to have authority over others. As far as I am aware there are two types of authority that can hold between individuals. The first is epistemic authority. Epistemic authority is authority based on a superior epistemic position to those subject to that authority. A good example is the authority of a physician. Imagine that you have a persistent headache that will not go away. You could consult a medical encyclopedia or Wikipedia. Alternatively, you could visit your physician and ask her what to do. Suppose she diagnoses you with migraine and prescribes

\footnotetext{
${ }^{36}$ Assuming, of course, that the law has authority. This is not a trivial assumption. For a critical discussion, see A. John Simmons, Moral Principles and Political Obligations (Princeton University Press, 1979).
} 
sumatriptan (a well known medicine against the effects of migraine). Now you have a reason to take sumatriptan. Your reason is that she prescribed it. Why is that a reason? Because your physician is in a better epistemic situation than you are with regards to the considerations that are relevant for your condition. She is, in other words, an epistemic authority. It is not the case that her prescription merely reports or transfers the reasons for taking sumatriptan (the specifics of your migraine, the biochemical properties of sumatriptan). Rather, you take her word for it: it is her saying so that provides your justification for taking sumatriptan. Like all genuine authorities, the authority of your physician is limited. Were she to prescribe, say, liberal daily doses of heroine, her prescription would have no authority. The scope of what she can prescribe is limited. Furthermore, she has discretion. Instead of sumatriptan, she could prescribe any of the other available triptans, and you would still have reason to obey her prescription. Note, moreover, that it need not be the case that sumatriptan is the best medicine for you. It may very well be that naratriptan is better for you. Still, since you are in no position to know and she is, you have reason to follow her prescription. The physician's discretion extends to less than optimal options. Epistemic authority, then, issues content-independent reasons that make a practical difference, and is limited and discretionary. Notice that epistemic authority is not absolute. Nothing stops you from seeking a second opinion. Even if the second opinion overrules the prescriptions of the first physician, that prescription still carries weight in determining what to do. Hence, the prescriptions of an epistemic authority are authoritative reasons and not categorical requirements.

Intentions can have such epistemic authority as well. For example, for a while I received unsolicited phone calls usually around dinnertime from phone companies trying to persuade me to switch to a different provider. Because dinnertime is hectic (food needs to be cooked, kids need to be fed, etc.) it is hard to come to a judgment about the merits of their proposals. Therefore, I have decided not to conduct that kind of business over the phone. In forming this intention, I have exercised authority over myself. At dinnertime my capacity for judging the merits of the various proposals is impeded. My decision not to conduct this kind of business over the phone at dinnertime was made under more favorable epistemic circumstances. My earlier decision has authority because it was made under more conducive circumstances. My reason for refusing the offer to switch phone plan is my earlier decision. Hence, I have a content-independent reason: it is not what I have decided that gives me reason, but the fact that I decided that is my reason. The authority of my decision is not absolute: I can revise my decision when I believe a really good opportunity is there.

However, the weight of that consideration has to be higher to accept the offer than it has to be in the absence of an intention not to conduct business over the phone. The epistemic authority of my intention is limited: if I decided to throw the phone out of the window next time I receive a dinner time call, then, presumably, that decision does not carry any weight when the phone company calls. The authority of my intention comes with discretion: I could have decided to accept an offer if it meets certain criteria, I could have decided to ask for written materials to consider their offer at a more appropriate time. All of these things I could have adopted as an intention in order to deal with the limitations on my capacity for coming to a well-considered decision during dinnertime. Note that my discretion even extends to adopting less than optimal courses of action. Maybe a particular offer really is a 
good deal. However, in the light of my earlier decision, I am justified in refusing. The epistemic authority of intentions is not a surprising or accidental feature, for if we take seriously the constraints on our deliberation, this is exactly what we would expect. The rationale for forming intentions is to cope with the heat-of-the-moment, on-the-spot constraints on our deliberation. It can only do that if the future-oriented intentions we formed then structure our deliberations now.

Intentions, therefore, sometimes have epistemic authority. Notice, however, that they need not necessarily have such authority. If the agent decides something that is beyond the limits of her authority or if the agent is not in an epistemic superior position relative to the time of execution, its adoption does not give the agent a content-independent reason to do as decided. So it is not the case that intentions always bootstrap reasons into existence. In this way, the exercise of epistemic authority over one's future selves does not result in questionable bootstrapping. Intentions only give reasons if they fall within the scope of the background reasons, i.e., within the limits of the authority, and if they are issued from an epistemic superior position. So while intentions do (sometimes) bootstrap reasons into existence, this bootstrapping is not troubling.

\section{THE COORDINATIVE AUTHORITY OF INTENTIONS}

Epistemic authority is one of the ways in which individuals can exercise authority over one another. The other way in which authority can be exercised is through coordination. This typically will be the case when there is a kind of collective action problem that requires mutual adjustment in behavior. For example, imagine that the Titanic is sinking and all the passengers want to abandon the vessel as quickly as possible. The Titanic is a big ship and carries lots of passengers so it is not obvious how each individual is supposed to do that, independent of what the other passengers are going to do. Suppose that the life boats carry only a limited number, then my decision to go to the first lifeboat on the left depends on where other passengers are going. If lots of others will make for that lifeboat, I am better of trying to get into the first lifeboat on the right. But of course, the same holds for each other individual passenger. We face a coordination problem: for each of us to achieve our goals we depend on what others will do and vice versa. These are all the reasons we have. Suppose at that moment the captain appears on the bridge and orders, say, the passengers in the salon to go to the first lifeboat on the left and the other passengers to go to the lifeboat on the right. Now each of the passengers in the salon will have a reason to go to the left. The passengers from the other decks will expect the other passengers in the salon to go to the left, so they should go to the right. And because they will go to the right, the passengers from the salon should go to the left, for there they are now assured they will find a place in the left lifeboat. The captain in this little story has exercised authority. He does not have this authority (just) based on his superior experience and knowledge of what to do in situations like this. Rather, through his commands the passengers are able to achieve successful coordination. The captain's commands give each passenger reason to expect what others will do and where he or she can find a place in a lifeboat. The captain's authority is limited. Were he to command us all to assemble in the salon in order to listen to the orchestra playing, he would not have given us any reason to go there. By ordering some 
to go left and others to go right, he has given us a reason to do as he told us. Notice that the captain has discretion. He could have ordered the salon passengers to go to the lifeboat on the right; he could have ordered women and children to go there, etc. There are plenty of ways to abandon ship in an orderly fashion. Notice, furthermore, that the particular order of the captain need not be the very best way to abandon ship. The fact that he ordered it and that it is good enough in comparison to no coordination at all, gives the passengers reason to do as they are told. Note, finally, that the reason that the captain gives the passengers is content-independent: it is the fact that he ordered so-and-so that gives them reason to do as they are told, not what he has ordered them to do.

Can intentions have similar authority? Elsewhere I have argued that they can. ${ }^{37}$ Bratman explicitly mentions one way in which intentions achieve coordination. ${ }^{38}$ By their hierarchical nature, intentions achieve coordination over time. I hesitate to adopt this suggestion here. There is no mutual adjustment in behavior between my selves over time as there is between individuals. Me at $\mathrm{t} 2$ cannot do anything that would influence the decisions of me at $\mathrm{t} 1$. Some argue that therefore the only kind of authority intentions exercise is epistemic. ${ }^{39}$ However, that is not correct. There are other ways in which intentions do exercise authority that reminds us of the way the captain of the Titanic exercised authority over the passengers.

Like most mothers, Mom loves her two children, Alice and Bill. She would like to give them both a treat. Unfortunately, she can give only one of them a treat. Since both children are equally deserving, needy and desirous, there is no reason for preferring either child.

Therefore, Mom is indifferent between the outcome in which Alice receives the treat (A), and the outcome in which Bill receives the treat (B). Rather than just arbitrarily picking $A$ or $B$, she should do so in a fair manner. She should flip a fair coin and let it decide who gets the treat. ${ }^{40}$ Note that this is fair: giving the treat to one of her children using this device is better (since fair) than giving it to one of them straightaway. Assuming for now that flipping the fair coin is the only method available Mom has two possible courses of action available that would do the trick. She could do A (i.e., give Alice the treat) if 'heads' comes up and B when 'tails' comes up. Alternatively, she could decide to do B if 'heads' comes up and A if 'tails' comes up.

Suppose that Mom has decided for the former. That is, she has formed at $\mathrm{t} 1$ an intention of the form ' $A$ if heads; $B$ if tails'. She then flips the coin and heads comes up at t2. Again she faces the choice between $A$ and $B$. Both children are still equally deserving, needy and keen on the treat, so it still seems that the reasons are equally strong. However, that is incorrect. Having made the decision to do $A$ if heads comes up makes it the case that it is fair to do $A$ now that heads has come up. Bill cannot complain that he is as needy and deserving as Alice.

\footnotetext{
${ }^{37}$ Bruno Verbeek, "Rational Self-Commitment," in Rationality and Commitment, ed. Fabienne Peter and Hans Bernhard Schmid (Oxford: Oxford University Press, 2007), 150-174; Verbeek, “A Limited Defense of Voluntarism in Practical Reason."

${ }^{38}$ Bratman, Intention, Plans, and Practical Reason.

${ }^{39}$ Den Hartogh, "The Authority of Intention."

${ }^{40}$ Or any other fair way - i.e., a way that gives equal weight to $A$ and $B$ - to break the tie between $A$ and $B$ in a fair manner.
} 
Nor can he demand Mom to flip the coin again, claiming that after flipping the coin is better than just arbitrarily giving it to Alice. He has had his chance. Mom's decision thus has created a reason of fairness to give the treat to Alice. In other words, in this situation Mom's earlier decision has created a reason that did not exist before.

Notice that here too Mom's authority is limited. She is not allowed to settle who should get the treat in an unfair manner. Also, Mom has discretion: there are lots of fair ways of settling the question as to who should get the treat. Mom's decision makes a practical difference. Without it, there would still be indifference as to who should get the treat. Notice, finally, that Mom's decision has created a content-independent reason. This is a bit more complicated than in the case of epistemic intentional authority. What is Mom's reason for giving the treat to $A$ ? Because it is fair. Why is it fair? Because it is what the coin flip dictated her to do. Why is that what the coin flip dictated her to do? Her initial decision to observe the outcome of the coin flip gave her this reason. In other words, because this is what she decided to do. So here too, we see that intentions can give an agent reasons authoritatively. The claim that intentions have authority, therefore, is plausible. It accounts for the normative phenomenology of intentions while at the same time avoiding questionable bootstrapping.

\section{CONCLUSION}

In this essay, I argued, first that there are good reasons to accept that intentions come with normative pressure. These pressures include demands for consistency with other attitudes of the agent, such as his beliefs, his other intentions, the means to be intended, as well as inertia. These demands create a challenge for philosophers: to account for these pressures without reverting to questionable bootstrapping. I discussed three alternative views that try to make sense of this normative phenomenology. The first view, myth theory, denies that intentions have any normative pressure on the agent and presents an explanation of how this nevertheless seems to be the case. It is, therefore, a species of error theory. I argued that myth theory could not be maintained in the light of all the specific normative pressures of intentions. The second view I discussed, two-flavor theory, accepts that intentions create normative pressure on the agent, but denies that this pressure is that of reasons. Instead, the adoption of an intention puts the agent under wide-scoped rationality requirements. I argued that two-flavor theory is implausible when considering the inertia of intentions as well as when one wonders whether there are any reasons to observe the requirements of rationality in the first place.

I then proceeded to suggest a third view: the authority view. On this view intentions do sometimes create reasons for the agent. However, as with myth theory, this is not always and necessarily the case. Secondly, these reasons are constrained by all kinds of background considerations that both limit the authority of the agent over herself and at the same time give her discretion. The authority view does imply that intentions themselves come with normative pressure just like two-flavor theory.

Of course, this is not a full defense of the authority view. A proper defense will have to point out how authoritative intentions have the specific normative pressures associated with 
intentions as well as answer a number of additional objections specifically targeted the authority view. All that I have tried to do here is suggest an alternative view to the prevailing doctrines. 


\section{REFERENCES}

Bratman, Michael. Faces of Intention: Selected Essays on Intention and Agency. New York: Cambridge University Press, 1999.

- - - Intention, Plans, and Practical Reason. Cambridge: Harvard University Press, 1987.

- - . "Practical Reasoning and Acceptance in a Context." Mind: A Quarterly Review of Philosophy 101, no. 401 (1992): 1-15.

- - - Structures of Agency: Essays. Oxford University Press, 2007.

Bratman, Michael E. "Cognitivism About Practical Reason (Review of Practical Reflection, by J. David Velleman)." Ethics 102, no. 1 (1991): 117-.

- - . "Intention Rationality." Philosophical Explorations 12, no. 3 (2011): 227-241.

- - . "Intention, Practical Rationality, and Self-governance." Ethics 119, no. 3 (2009): 411443.

Broome, John. "Are Intentions Reasons? And How Should We Cope with Incommensurable Values?" In Practical Rationality and Preference: Essays for David Gauthier, edited by Arthur Ripstein and Christopher Morris, 98-120. Cambridge: Cambridge University Press, 2001.

- - "Does Rationality Give Us Reasons?" Philosophical Issues 15, no. 1 (2005): 321-337.

- - . "Normative Requirements." Ratio: An International Journal of Analytic Philosophy 12, no. 4 (1999): 398-419.

- - . "Practical Reasoning." In Reason and Nature: Essays in the Theory of Rationality, 85111. Oxford: Oxford University Press, 2002.

- - . "Reasons." In Reason and Value: Essays on the Moral Philosophy of Joseph Raz. Oxford: Oxford University Press, 2004.

---. "Reply to Southwood, Kearns and Star, and Cullity." Ethics 119, no. 1 (2008): 96-108.

- - . "The Unity of Reasoning?" In Spheres of Reason: New Essays in the Philosophy of Normativity, edited by Simon Robertson, 62-92. Oxford: Oxford University Press, 2009.

-- - "Wide or Narrow Scope." Mind 116, no. 462 (April 2007): 359-370.

Brunero, John. "Against Cognitivism About Practical Rationality." Philosophical Studies 146, no. 3 (2009).

- - "Are Intentions Reasons?" Pacific Philosophical Quarterly 88, no. 4 (2007): 424-444.

- - - "Instrumental Rationality, Symmetry and Scope." Philosophical Studies 157, no. 1 (2012): 125-140.

Chang, Ruth. "Do We Have Normative Powers?" St. Louis, 2010.

- - - "Voluntarist Reasons and the Sources of Normativity." In Reasons for Action, edited by David Sobel and Steven Wall. Cambridge University Press, 2009.

Cohen, L. Jonathan. An Essay on Belief and Acceptance. Oxford: Clarendon Press, 1992.

- - - "Belief and Acceptance." Mind 98, no. 391 (July 1989): 367-389.

Enoch, David. "Agency, Shmagency: Why Normativity Won't Come from What Is Constitutive of Action." Philosophical Review 115, no. 2 (2006): 169-198.

Foot, Philippa. "Morality as a System of Hypothetical Imperatives." Philosophical Review 81, no. 3 (1972): 305-316.

Harman, Gilbert. Change in View: Principles of Reasoning. Cambridge: MIT Press, 1986.

Den Hartogh, Govert. "The Authority of Intention." Ethics 115, no. 1 (2004): 6-34.

Holton, Richard. "Intention and Weakness of Will." The Journal of Philosophy 96, no. 5 (1999): 241-262.

-- -. Willing, Wanting, Waiting. Oxford [Eng.] ; New York: Clarendon Press ; Oxford University Press, 2009.

Joyce, Richard. The Evolution of Morality. MIT Press, 2006.

Kant, Immanuel. Groundwork for the Metaphysics of Morals. Edited by Lara Denis. Translated by Thomas K. Abbott. Oxford University Press, 1785. 
Kolodny, Niko. "State or Process Requirements?" Mind 116, no. 462 (2007): 371-385.

- - . "Why Be Rational?" Mind 114, no. 455 (2005): 509-563.

Lord, Errol. "Having Reasons and the Factoring Account." Philosophical Studies 149, no. 3 (2010).

Raz, Joseph. "Authority, Law and Morality." Monist: An International Quarterly Journal of General Philosophical Inquiry 68, no. 3 (1985): 295-324.

- - . The Morality of Freedom. Oxford: Oxford University Press, 1986.

- - . "The Myth of Instrumental Rationality." Journal of Ethics and Social Philosophy 1, no. 1 (2005).

- - . "The Problem of Authority: Revisiting the Service Conception." Minnesota Law Review 90, no. 4 (2006): 1003-1044.

Reisner, Andrew. "Unifying the Requirements of Rationality." Philosophical Explorations: An International Journal for the Philosophy of Mind and Action 12, no. 3 (November 5, 2009): $243-260$.

Scanlon, Thomas. What We Owe to Each Other. Belknap Press of Harvard University Press, 1998.

Schroeder, Mark. Slaves of the Passions. Oxford University Press, 2007.

- - . "The Scope of Instrumental Reason." Philosophical Perspectives 18, no. 1 (2004): 337-364.

Setiya, Kieran. “Cognitivism About Instrumental Reason." Ethics 117, no. 4 (2007): 649-673.

Simmons, A. John. Moral Principles and Political Obligations. Princeton University Press, 1979.

Tenenbaum, Sergio. Appearances of the Good: An Essay on the Nature of Practical Reason. Cambridge University Press, 2007.

Ullmann-Margalit, Edna, and Sidney Morgenbesser. "Picking and Choosing." Social Research 44 (1977): 757-785.

Velleman, J. David. “Epistemic Freedom." Pacific Philosophical Quarterly 70, no. March (1989): 73-97.

- - - "The Guise of the Good." Nous 26, no. 1 (1992): 3-26.

- - . The Possibility of Practical Reason. Oxford: Oxford University Press, 2000.

- - - "What Happens When Someone Acts." Mind 101, no. 403 (1992): 461-481.

Verbeek, Bruno. "A Limited Defense of Voluntarism in Practical Reason." Unpublished Manuscript. Leiden, February 12, 2012.

- - - "Feasible Intentions." Unpublished Manuscript. Leiden, November 2010.

- - - "Rational Self-Commitment." In Rationality and Commitment, edited by Fabienne Peter and Hans Bernhard Schmid, 150-174. Oxford: Oxford University Press, 2007.

- - . "The Authority of Norms." American Philosophical Quarterly 44, no. 3 (2007): 245258.

Williams, Bernard. "Internal and External Reasons." In Moral Luck, edited by Bernard Williams, 101-113. Cambridge: Cambridge University Press, 1981. 